\title{
Semantic and Phonemic Verbal Fluency Performance in Patients with General Anxiety Disorders and Allostatic Load under Alprazolam Treatment
}

\author{
Carlos A. Soria ${ }^{1}$, Carolina Remedi1 ${ }^{1}$ Luciana D’Alessio ${ }^{2 *}{ }^{\circledR}$, Emilio J. A. Roldán ${ }^{3}$ \\ ${ }^{1}$ Institute of Biosciences Henri Laborit, Córdoba, Argentina \\ ${ }^{2}$ Buenos Aires University, CONICET, Buenos Aires, Argentina \\ ${ }^{3}$ Scientific Direction Gador SA, Buenos Aires, Argentina \\ Email: ^lucianad@conicet.gov.ar, ^luladalessio@gmail.com
}

How to cite this paper: Soria, C.A., Remedi, C., D’Alessio, L. and Roldán, E.J.A. (2019) Semantic and Phonemic Verbal Fluency Performance in Patients with General Anxiety Disorders and Allostatic Load under Alprazolam Treatment. Open Journal of Psychiatry, 9, 138-152.

https://doi.org/10.4236/ojpsych.2019.92011

Received: February 22, 2019

Accepted: March 23, 2019

Published: March 26, 2019

Copyright $\odot 2019$ by author(s) and Scientific Research Publishing Inc. This work is licensed under the Creative Commons Attribution International License (CC BY 4.0).

http://creativecommons.org/licenses/by/4.0/

(c) (i) Open Access

\begin{abstract}
Purpose: Anxiety disorders are frequently associated with chronic stress with possible cognitive consequences. The aim of this study was to determine the verbal fluency performance in a cohort of patients with anxiety disorders and allostatic load, treated with alprazolam during 12 weeks. Methods: Patients with GAD (general anxiety disorders, DSM IV), with $>6$ in Hamilton Anxiety Rating Scale (HAM-A), neuroticism > 18 (NEO-FFI inventory), and normal Mini-Mental State Examination were included. Clinical and Psychiatric examination, Allostatic Load Index and cognitive assessment were analyzed before and after 12 weeks of treatment. The phonemic and semantic verbal fluency tests were determined in all patients. The scoring for each fluency task was determined by counting the number of correct words. The total score from each semantic and phonemic verbal task was analyzed comparing the individual score with normal data controlled by age and sex. Patients with scores $>-2$ standard deviation (SD) from normative data were considered impaired. Results: Fifty-four patients completed the semantic verbal fluency test before treatment and fifty patients completed after treatment. According to the z-scores before treatment 7 patients of $54(12.9 \%)$ had verbal fluency impairments. After treatment none patients showed semantic verbal fluency deficits but 3 patients of 50 (6\%) showed phonemic impairments. Impaired group was significantly associated with an older age before treatment $(\mathrm{p}=$ $0.033)$ and with a similar tendency but not significant $(\mathrm{p}=0.09)$ after treatment (Student $t$ test). Conclusion: In this study older age factor was associated with verbal fluency impairment in GAD patients. Stratified treatments
\end{abstract}


analyzing age and sex factors, including allostatic load measurements and cognitive assessments may be useful tools to determine the effectiveness and the safety of psychopharmacological treatments.

\section{Keywords}

Verbal Fluency Test, Chronic Stress, Allostatic Load, Sex, Age

\section{Introduction}

Stressors trigger physiological and behavioural responses that are aimed at reinstating homeostasis. If the stress response is inadequate or excessive and prolonged (chronic stress), the cost of reinstating homeostasis might become too high and predisposed individuals at an increased risk of (mental) illness such as general anxiety disorder [1] [2]. Chronic stress has been demonstrated to induce functionally-relevant effects on hippocampus and prefrontal cortex brain neuroplasticity due to hypothalamic-pituitary-adrenal axis (HPA $)^{1}$ hyperactivity, traduced on impairments in cognition [3]-[8].

Verbal and non-verbal fluency performance have been previously studied in patients with attention deficit hyperactivity disorder [9] and in patients with obsessive compulsive disorder [10] and also in subjects with stress related conditions such as neuroticism [11], showing lower scores and impairments among these patients. In this line, other authors have been proposed that anxiety may modify neural activation during the performance of verbal fluency tasks, executive functions that are dependent on the frontal lobe function [12].

On the other side, the use of drugs such as benzodiazepines is effective in promptly reducing anxiety scores but may have controversial effects on cognition after long term use [13]-[18]. Nevertheless, there are not conclusive findings regarding verbal fluency, an executive function which depends on frontal lobe functions, in patients with general anxiety disorders treated with benzodiazepines [18] [19].

The rate of the outpatients' use of benzodiazepines has been increased substantially in the last years, especially among clinicians, psychiatrists and neurologists [20]; indeed clinical studies are continually needed to determine safety in long term uses. The GEMA project (Gador Study of Stress Modulation by Alprazolam) [21] consists of a series of consecutive studies performed on a group of high symptomatic outpatients with general anxiety disorder (GAD) ${ }^{2}$ associated with chronic stress, determined by high allostatic load (AL) levels (indicators for the functioning of the main potentially stress affected systems) [22] [23] and neuroticism (a clinical condition well-known as a stress vulnerability factor and defined as an exaggerated response to psychosocial stressors with intense emotional reaction) [24] [25] [26] [27].

${ }^{1}$ (HPA) Hypothalamic-pituitary-adrenal axis.

${ }^{2}(\mathrm{GAD})$ General Anxiety Disorder 
In a previous analysis performed by our group in the same cohort of patients, we analyzed the AL index and determined the effects of sex and age on allostatic load variables before and after treatment [28]. In this study we found that female sex was associated with higher levels of anxiety with a better profile in the same allostatic load variables such as cardiovascular ones. Hereby, in the present report we aimed to determine the verbal fluency performance at basal conditions (before treatment) and after 12 weeks of treatment with alprazolam (a positive allosteric modulator of GABA A receptor), including sex and age as influential factors.

\section{Methods}

In this prospective study patients were recruited during 3 years up to 2014. The database is currently locked and subjected to multiple analyses. Inclusion criteria were Hamilton Anxiety Rating Scale $(\mathrm{HAM}-\mathrm{A})^{3}$ [29] > 6, a minimum score of 18 points in the NEO-FFI neuroticism scale [30] and at least one positive criterion for AL load index modified from Seeman and Crimmins 2003 [22] (clinical manifestations were under personalized medical treatment and were stable). All patients had a normal performance in the Mini-Mental State Examination [31] with general good vision and hearing with or without the use of aids. Exclusion criteria were: subjects with depression and/or other comorbid diseases listed under axis I of the DSM-IV, (American Psychiatric Association, 1994), patients taking psychotropic drugs, sympathomimetic, corticosteroid and/or any other medication that might interact with alprazolam; persons who were hypersensitive to drugs; with confirmed or suspected gestation; women likely to become pregnant during the study; patients with an important clinical condition that required treatment modification and that might interfere with the study treatment or evaluation methods.

The protocol was evaluated in accordance with the code of ethics of the World Medical Association (Declaration of Helsinki) and Argentine clinical practice guideline, by the Independent Ethics Committee of Foundation for Pharmacological Studies and Drugs, Buenos Aires and then submitted to the national regulatory authority (ANMAT, Disposition \#61409-8) and to the provincial regulatory authority, under the responsibility of the Ministry of Health of Córdoba Province (Dossier \#1296). The trial is also registered at WHO (Word Health Organization $)^{4}$ trial registration data set. Results were reported to the Argentine regulatory agency ANMAT in accordance with regulations in force. All patients signed the informed consent form.

\subsection{Clinical Assessment}

In this trial all determinations were analyzed periodically (see Soria et al. 2005 for details) [21]. In the present study, we report the changes in verbal fluency

${ }^{3}$ (HAM-A) Hamilton Anxiety Rating Scale.

${ }^{4}$ (WHO) World Health Organization. 
tests and the correlations with clinical variables, after 12 weeks of treatment with reference to the basal status.

Anxiety assessment: All patients included in this study met criteria for general anxiety disorder codified in Axis I of DSM IV (American Psychiatric Association) [32], and psychiatric assessment was determined by experimented clinical psychiatrists. In all patients the HAM-A [29] of 14 items was determined, (>6 points indicated anxiety and $\geq 15$ points indicated moderate to severe anxiety).

Allostatic Load assessment: For measuring AL index, 18 clinical and laboratory parameters were determined during the morning (10 \pm 1 hour AM). One point was added for each abnormal parameter up or under the cut off points according to Crimmins and Seeman criteria modified (2) [1]: 1-Systolic blood pressure > $140 \mathrm{mmHg}$ and/or; 2-diastolic pressure >90 mmHg; 3-BMI2 (body mass index) $>25$; 4 -waist-hip ratio (indexes of adipose tissue deposition) more than $>1$ in men and $>0.8$ in women; 5-total cholesterol $>200 \mathrm{mg} / \mathrm{dl} ; 6-\mathrm{LDL}$ (low density lipoprotein) > $120 \mathrm{mg} / \mathrm{dl}$; 7-HDL (high density lipoprotein) $>37$ $\mathrm{mg} / \mathrm{dl} ; 8$-total cholesterol/HDL ratio $>3.5 \mathrm{mg} / \mathrm{dl}$; 9-triglycerides $>200 \mathrm{mg} / \mathrm{dl}$; 10 -creatinine $>1.2 \mathrm{mg} / \mathrm{dl} ; 11$-albumin $<3.5 \mathrm{~g} / \mathrm{dl} ; 12$-C-reactive protein $(\mathrm{CRP})>$ $7.1 \mathrm{mg} / \mathrm{L} ; 13$-fibrinogen $>400 \mathrm{mg} / \mathrm{dl} ; 14$-glycated hemoglobin > $6 \mathrm{mg} / \mathrm{dl}$; 15-salivary cortisol > $32 \mathrm{nM}$; 16-salivary methoxy-hydroxy-phenylglycol (MHPG) (noradrenaline metabolite) > $2750 \mathrm{nM} ; 17$-serum dehydro-epi-androsterone (DHEA) $<80 \mathrm{ng} / \mathrm{ml}$ in men and $<35 \mathrm{ng} / \mathrm{ml}$ in women; 18 - serum noradrenaline levels $>100 \mathrm{pg} / \mathrm{ml}$.

Cognitive assessment: The phonemic and semantic verbal fluency tests were determined in all patients [33]. On the semantic verbal fluency task participants had to name as many animals as possible within two minutes. Words that were not identifiable as animals were considered rule violations and the examiner recorded all correct words. On the phonemic verbal fluency task the patients were asked to name within 2 minutes, as many different words as possible beginning with the letter $\mathrm{p}$. Words beginning with another letter and/or perseverations were considered rule violations. The scoring for each fluency task was determined by counting the number off correct words excluding the number of rule violations and repetitions. The tests were applied after 6 hours since the last administration of alprazolam (nadir plasma). Cognitive tests were blinded to the evaluator. In this report we analyzed the scores at two moments, before and after treatment. The total score from each semantic and phonemic verbal tasks were analyzed comparing the individual score with normal data controlled by age and sex. Patients with scores $>-2$ standard deviation (SD) from normative data controlled by age and sex were considered impaired [33].

\subsection{Treatment Instauration}

Patients admitted into the study were given alprazolam tablets (Alplax ${ }^{\circledR}$, Gador SA, Buenos Aires; batch number 03730), in a flexible dosing regimen within 0.25 
to $1 \mathrm{mg}$ t.i.d. (three times a day), which enabled a dose-response analysis for the variables under investigation. Individual doses were determined according to clinical criteria by the researcher responsible for each patient, and the lowest effective dose was administered in each case. The alprazolam's dosage schedule was maintained for 12 weeks. Subsequently, the investigator decided to continue or discontinue treatment. All participants have been warned about alprazolam's depressant effects and the possible risks in activities that required alert. Alcohol consumption during the observational period was not recommended. Patients were also monitored to detect risk of suicide and/or overdose. All adverse events were monitored according to good clinical practice standards of the local regulatory authority; National Administration of Drugs, Foods and Medical Devices (ANMAT) and the Ministry of Health, Province of Córdoba.

\subsection{Statistics}

Descriptive statistics of quantitative variables were determined and compared. The sample size was calculated considering changes in variables higher than $25 \%$ with a $1-\beta$ power of $0-80$ to be detected. Statistical significance was considered at $\mathrm{p}<0.05$ (2-sided; $1-\beta$ power $\geq 0.80$ ). To analyze sex and age factors $(\geq$ or $<50$ years old) effects on total scores of cognitive parameters, a general univariate lineal model (Two-way ANOVA) was applied for each AL variable measured before and after treatment. Interactions between factors were also analyzed, and the effect size was calculated using the partial eta squared $\left(\mathrm{hp}^{2}\right)$. Effect size $>0.09$ was considered strong, between 0.02 and 0.09 is moderate and $\leq 0.02$ is statistically significant but weak. Student $t$ test was determined to compare impaired versus no-impaired group. Spearman (non-parametric) and/or Pearson (parametric) tests were used to determine the correlation coefficient: $r \geq 0.80$ and $p<$ 0.05 (2-sided) was considered as strong correlation, $\mathrm{r}=0.50<\mathrm{r}<0.80$ and $\mathrm{p}<$ 0.05 (2-sided), was considered a moderate correlation and $\mathrm{r} \geq 0.3$ and $<0.5$ and $\mathrm{p}<$ 0.05 (2-sided) was considered a low correlation [34].

\section{Results}

In this analysis, fifty-four patients completed the semantic verbal fluency test (35 women and $19 \mathrm{men}$ ), and 53 (35 women and $18 \mathrm{men}$ ) the phonemic verbal fluency test at basal. According age, at basal 26 patients had $\geq 50$ years old, and 28 patients $<50$ years. After treatment fifty patients completed both semantic and phonemic verbal fluency tests. Changes in the individual allostatic variables in this sample and psychiatric variables were described in detail in a previous publication [28]. The VFT scores according age a sex are resumed in Table 1 and Table 2. No differences were found regarding sex and age factors in this sample analyzing the total score (Two way ANOVA) either at basal or at week 12. In a second analysis, the z-scores corrected by age and sex for each patient, were determined before and after treatment. Before treatment 7 patients of $54(12.9 \%)$ had verbal fluency impairments $(z$-score $>-2$ comparing with normative data 
Table 1. Sex differences in cognitive performance before and after treatment.

\begin{tabular}{|c|c|c|c|c|c|c|}
\hline $\begin{array}{l}\text { Clinical and } \\
\text { Cognitive } \\
\text { Assessments } \\
\text { (Scores) }\end{array}$ & Sex & $\mathbf{n}$ & $\mathrm{X}$ & SD & $\begin{array}{c}\text { Two-way } \\
\text { ANOVA = p value }\end{array}$ & $\begin{array}{c}\text { Partial eta } \\
\text { squared } \\
\left(\mathrm{hp}^{2}\right)\end{array}$ \\
\hline \multicolumn{7}{|c|}{$\begin{array}{l}\text { Hamilton Anxiety } \\
\text { Scale (HAM-A) }\end{array}$} \\
\hline \multirow{2}{*}{ Basal } & Females & 35 & 31.7 & 10.2 & \multirow{2}{*}{$3.7(1,50)=0.05$} & \multirow{2}{*}{0.069} \\
\hline & Males & 19 & 28.2 & 6.4 & & \\
\hline \multirow{2}{*}{ w12 } & Females & 31 & 14.4 & 5.7 & \multirow{2}{*}{$8.82(1,46)=0.005^{\star}$} & \multirow{2}{*}{0.161} \\
\hline & Males & 19 & 9.4 & 5.8 & & \\
\hline \multicolumn{7}{|c|}{ Total Allostatic Index } \\
\hline \multirow{2}{*}{ Basal } & Females & 35 & 5.4 & 2.3 & \multirow{2}{*}{$1.08(1,50)=0.30$} & \multirow{2}{*}{0.021} \\
\hline & Males & 19 & 6.0 & 2.2 & & \\
\hline \multirow{2}{*}{ w12 } & Females & 31 & 4.6 & 2.5 & \multirow{2}{*}{$2.13(1,46)=0.15$} & \multirow{2}{*}{0.044} \\
\hline & Males & 19 & 5.4 & 1.9 & & \\
\hline \multicolumn{7}{|c|}{$\begin{array}{l}\text { Verbal Fluency Test } \\
\quad \text { (Semantic) }\end{array}$} \\
\hline \multirow{2}{*}{ Basal } & Females & 35 & 20.0 & 5.2 & \multirow{2}{*}{$0.006(1,50)=0.94$} & \multirow{2}{*}{0.001} \\
\hline & Males & 19 & 20.0 & 4.8 & & \\
\hline \multirow{2}{*}{ w12 } & Females & 31 & 23.5 & 5.0 & \multirow{2}{*}{$0.45(1,46)=0.23$} & \multirow{2}{*}{0.03} \\
\hline & Males & 19 & 25.3 & 6.3 & & \\
\hline \multicolumn{7}{|c|}{$\begin{array}{l}\text { Verbal Fluency Test } \\
\text { (Phonemic) }\end{array}$} \\
\hline \multirow{2}{*}{ Basal } & Females & 35 & 12.9 & 3.9 & \multirow{2}{*}{$0.27(1,49)=0.6$} & \multirow{2}{*}{0.006} \\
\hline & Males & 18 & 12.1 & 4.8 & & \\
\hline \multirow{2}{*}{ w12 } & Females & 31 & 14.52 & 4.1 & \multirow{2}{*}{$0.25(1,46)=0.6$} & \multirow{2}{*}{0.021} \\
\hline & Males & 19 & 13.74 & 3.5 & & \\
\hline
\end{tabular}

W12: Week 12, $\mathrm{n}$ (number of patients), $\mathrm{X}=$ mean, $\mathrm{SD}=$ standard deviation. $\mathrm{hp}^{2}=$ Effect size. ${ }^{\star} \mathrm{p}<0.05$.

matched by age and sex); 5 patients showed impairments in semantic verbal fluency, 2 patients in phonemic verbal fluency and 1 showed both semantic and phonemic impairments. After treatment none patients showed semantic verbal fluency deficits but 3 patients of 50 (6\%) showed phonemic impairments (Figure $1)$.

In an ulterior analysis we compared the clinical variables (psychiatric, allostatic load and pharmacological variables), between impaired and no-impaired subjects before and after treatment. Impaired group was significantly associated to older age before treatment $(\mathrm{p}=0.033)$ with a tendency but not significant $(\mathrm{p}=$ 0.09) after treatment (Student t test) (Figure 2). Pearson correlations between allostatic load individual parameters and verbal fluency tasks (z scores), showed a low correlation between phonemic verbal fluency and noradrenaline levels after treatment $(r=0.31, p=0.03)$. Also a tendency to a negative correlation 
Table 2. Age differences in cognitive performance before and after treatment.

\begin{tabular}{|c|c|c|c|c|c|c|}
\hline $\begin{array}{c}\text { Clinical and Cognitive } \\
\text { Assessments } \\
\text { (Scores) }\end{array}$ & $\begin{array}{c}\text { Age } \\
(\text { Years = ys })\end{array}$ & $\mathbf{n}$ & $x$ & SD & $\begin{array}{c}\text { Two-way ANOVA } \\
\mathrm{F}(\mathrm{df})=\mathrm{p} \text { value }\end{array}$ & $\begin{array}{c}\text { Partial eta } \\
\text { squared } \\
\left(\mathrm{hp}^{2}\right)\end{array}$ \\
\hline \multicolumn{7}{|l|}{$\begin{array}{l}\text { Hamilton Anxiety } \\
\text { Scale (HAM-A) }\end{array}$} \\
\hline Basal & $\begin{array}{l}\geq 50 \mathrm{ys} \\
<50 \mathrm{ys}\end{array}$ & $\begin{array}{l}26 \\
28\end{array}$ & $\begin{array}{l}31.4 \\
30.9\end{array}$ & $\begin{array}{l}8.1 \\
8.3\end{array}$ & $0.01(1,50)=0.97$ & 0.001 \\
\hline w12 & $\begin{array}{l}\geq 50 \mathrm{ys} \\
<50 \mathrm{ys}\end{array}$ & $\begin{array}{l}24 \\
26\end{array}$ & $\begin{array}{l}13.1 \\
11.9\end{array}$ & $\begin{array}{l}6.4 \\
6.1\end{array}$ & $0.03(1,46)=0.90$ & 0.000 \\
\hline \multicolumn{7}{|l|}{$\begin{array}{l}\text { Total Allostatic } \\
\text { Load Index }\end{array}$} \\
\hline Basal & $\begin{array}{l}\geq 50 \text { ys } \\
<50 \text { ys }\end{array}$ & $\begin{array}{l}26 \\
28\end{array}$ & $\begin{array}{l}6.1 \\
5.1\end{array}$ & $\begin{array}{l}1.8 \\
2.4\end{array}$ & $3.31(1,50)=0.07$ & 0.062 \\
\hline w12 & $\begin{array}{l}\geq 50 \text { ys } \\
<50 \text { ys }\end{array}$ & $\begin{array}{l}24 \\
26\end{array}$ & $\begin{array}{l}5.7 \\
4.1\end{array}$ & $\begin{array}{l}2.1 \\
2.3\end{array}$ & $5.98(1,46)=0.02^{\star}$ & 0.115 \\
\hline \multicolumn{7}{|l|}{$\begin{array}{l}\text { Verbal Fluency Test } \\
\text { (Semantic) }\end{array}$} \\
\hline Basal & $\begin{array}{l}\geq 50 \text { ys } \\
<50 \text { ys }\end{array}$ & $\begin{array}{l}26 \\
28\end{array}$ & $\begin{array}{l}19.7 \\
20.3\end{array}$ & $\begin{array}{l}5.9 \\
4.1\end{array}$ & $0.01(1,50)=0.89$ & 0.001 \\
\hline w12 & $\begin{array}{l}\geq 50 \text { ys } \\
<50 \text { ys }\end{array}$ & $\begin{array}{l}24 \\
26\end{array}$ & $\begin{array}{l}24.4 \\
24.0\end{array}$ & $\begin{array}{l}5.8 \\
5.3\end{array}$ & $0.27(1,46)=0.63$ & 0.006 \\
\hline \multicolumn{7}{|l|}{$\begin{array}{l}\text { Verbal Fluency Test } \\
\quad \text { (Phonemic) }\end{array}$} \\
\hline Basal & $\begin{array}{l}\geq 50 \text { ys } \\
<50 \text { ys }\end{array}$ & $\begin{array}{l}26 \\
27\end{array}$ & $\begin{array}{l}12.1 \\
13.1\end{array}$ & $\begin{array}{l}4.1 \\
4.4\end{array}$ & $0.76(1,49)=0.80$ & 0.015 \\
\hline w12 & $\begin{array}{l}\geq 50 \mathrm{ys} \\
<50 \mathrm{ys}\end{array}$ & $\begin{array}{l}24 \\
26\end{array}$ & $\begin{array}{l}14.5 \\
13.9\end{array}$ & $\begin{array}{l}4.3 \\
3.5\end{array}$ & $0.69(1,46)=0.40$ & 0.015 \\
\hline
\end{tabular}

W12: Week 12, $\mathrm{n}$ (number of patients), $\mathrm{X}=$ mean, $\mathrm{SD}=$ standard deviation. $\mathrm{hp}^{2}=$ Effect size. ${ }^{*} \mathrm{p}<0.05$.

was found between DHEA plasmatic levels $(\mathrm{r}=-027, \mathrm{p}=0.04)$ and phonemic verbal fluency z-score at basal (Figure 3). Additionally, Pearson correlations between verbal fluency tests, showed an inverse correlation tendency between neuroticism score and phonemic verbal fluency score at basal $(\mathrm{r}=-0.258, \mathrm{p}=$ $0.068)$

\section{Discussion}

In this study we included a special sample of very symptomatic patients with GAD associated to AL (a clinical index of chronic stress) and neuroticism (a psychological condition associated to an exaggerated response to psychosocial stressors). These patients underwent long-term treatment (12 weeks) with alprazolam in low doses (1.5 to $3 \mathrm{mg} /$ day). The high-potency BZD alprazolam (a triazolo-benzodiazepine), produces a positive allosteric modulation of $\mathrm{GABA}_{\mathrm{A}}$ 


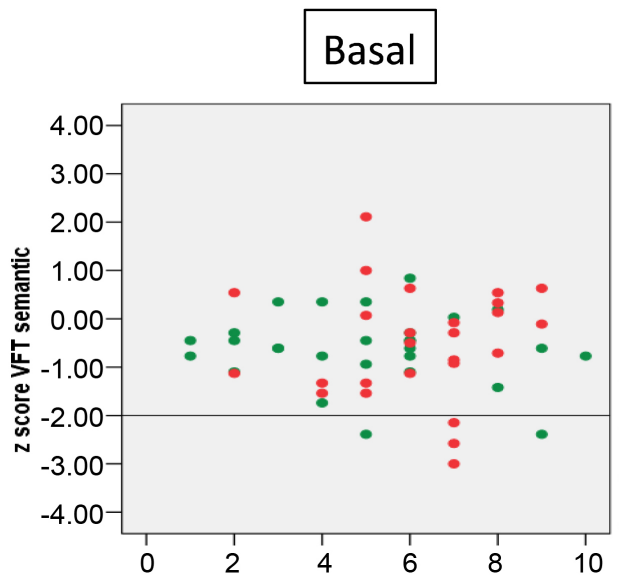

\section{2 weeks after treatment}
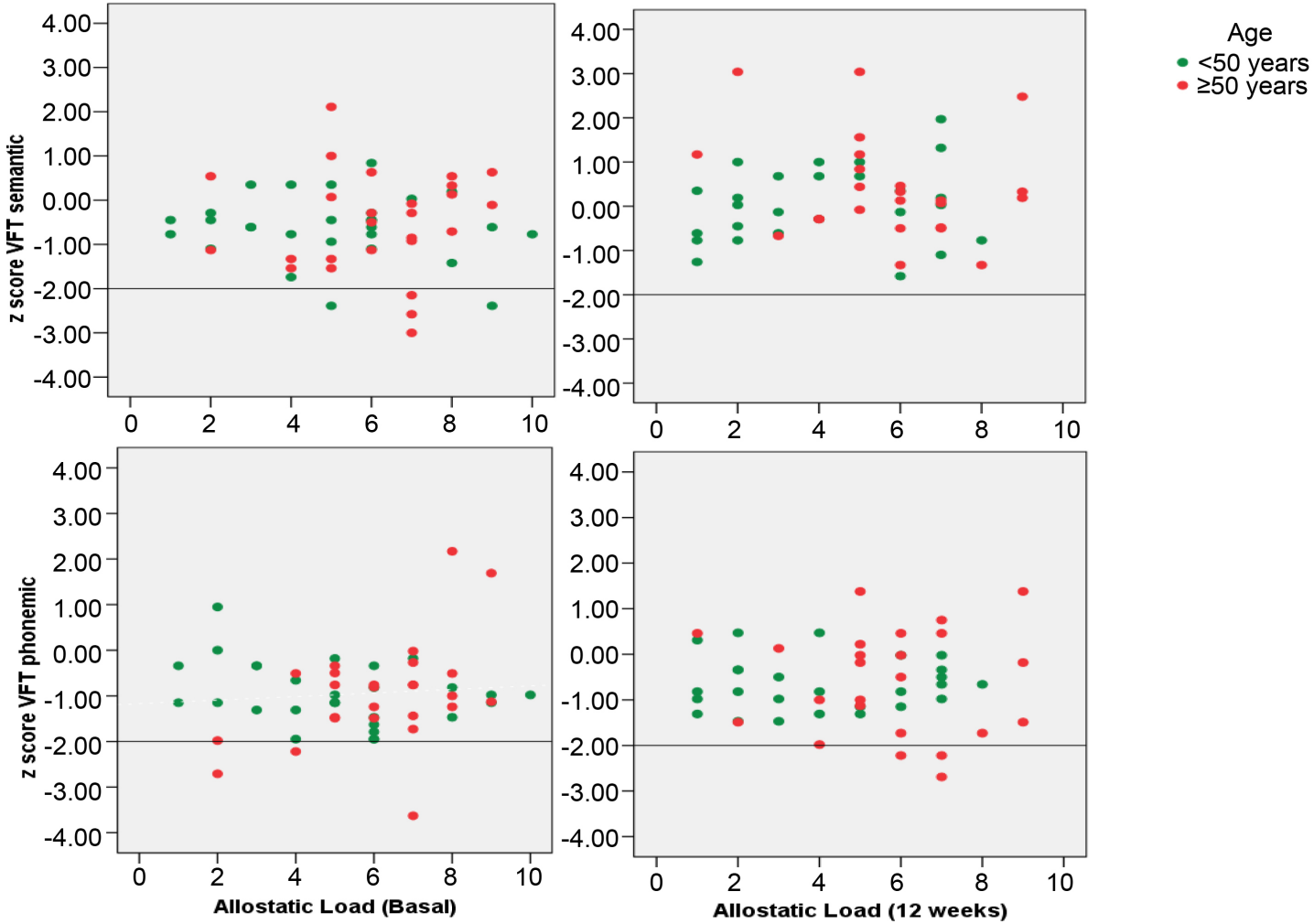

Figure 1. Verbal Fluency Test (VFT), semantic and phonemic z-scores in function of the allostatic load index in patients with general anxiety disorder treated during 12 weeks with alprazolam.
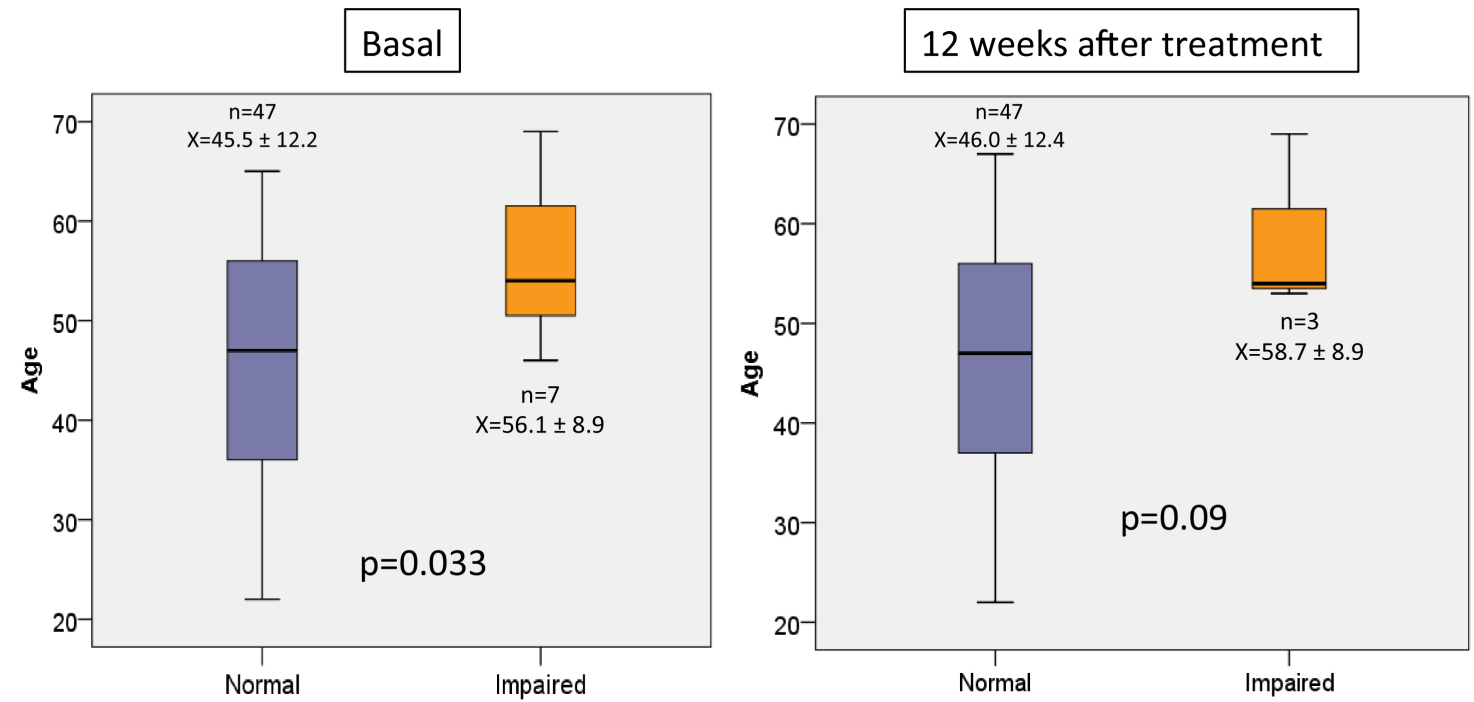

Figure 2. Age comparison of subjects with general anxiety disorder and allostatic load treated during 12 weeks with alprazolam according to the performance in the VFT (z-scores). Blue boxes represent patients with normal VFT (z-scores $\leq-2 \mathrm{SD})$, and orange boxes represent patients with impaired VFT (z-scores $>-2 \mathrm{SD})$.

receptor. Alprazolam administered in relatively low doses may has a positive effect on individuals with anxiety disorders associated with chronic stress, and has 


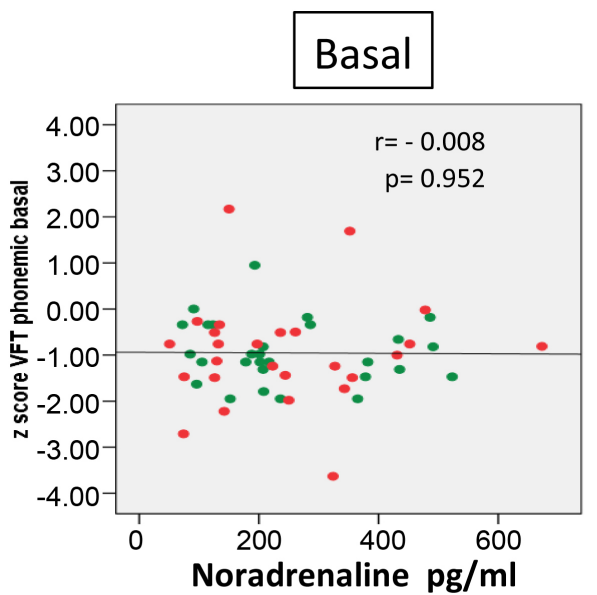

\section{2 weeks after treatment}
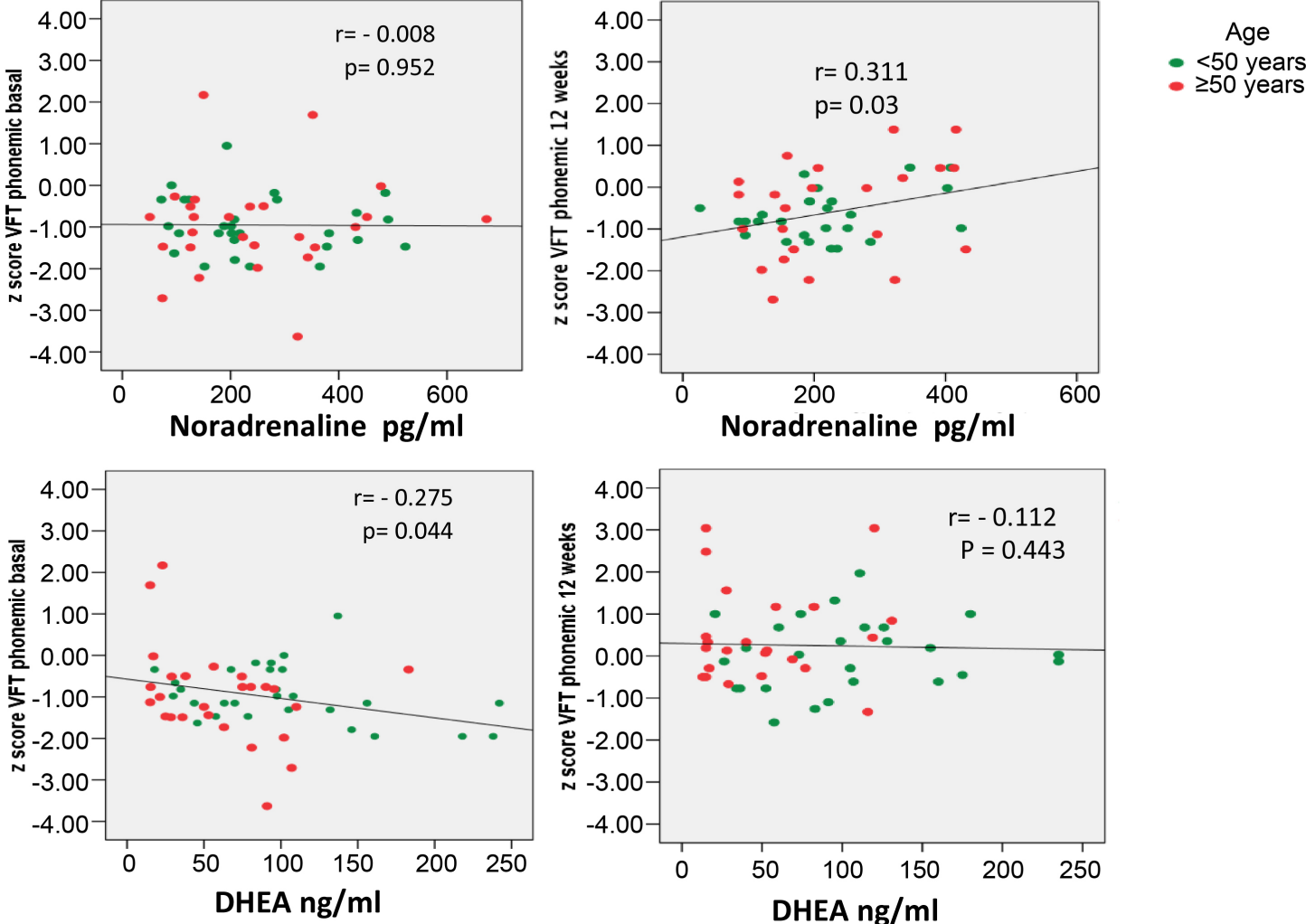

Figure 3. Pearson correlations between cognitive variables (Phonemic VFT) and allostatic load variables. Phonemic VFT inversely correlated with DHEA plasmatic levels at basal and positively correlated with noradrenaline plasmatic levels at 12 weeks.

been proposed to have less impact on cognitive functions because of the shorter acting and the lower doses required [18] [21]. Nevertheless, the risk of inducing pharmacological dependence and/or cognitive adverse events have been described, indeed it should be regarded with caution [13] [14] [15] [16] [17] [35] [36] [37]. In the present report, older age was the main factor involved in the verbal fluency alterations observed before and after alprazolam treatment. Before treatment a 13\% was found impaired. After treatment, phonemic but not semantic verbal fluency was found impaired in a few cases. Older age is a known factor involved in cognition impairment, and has been proposed as a warning factor for developing cognitive decline induced by drugs, particularly benzodiazepines [18] [36] [38]-[43]. Additionally, in this study, the noradrenaline levels showed a low correlation with verbal fluency scores after treatment, suggesting that noradrenergic function may be a potential regulator of these functions with a potential dual effect (deleterious effect in high levels but also in very low levels). Similar to this results, other researchers determined lower salivary levels of MHPG in anxious patients treated with alprazolam [24] [44] [45] and in normal subjects who received the drug [46]. Similarly to these authors, we described in a previous report the reduction of MHPG (the main noradrenaline metabolite) and 
noradrenaline, 12 weeks after treatment with alprazolam, contributing to reduce AL [28]. In this regard an increment of noradrenergic function was described in patients with anxiety disorders [47] [48]. Indeed, periodic dosages of allostatic load biochemical parameters may be an easy method to complete the clinical analysis during the follow up of treated patients.

Chronic stress has demonstrated to induce negative effects on cognitive functions and on emotional regulation, altering neuroendocrine and autonomic functions [8]. Chronic stress may impairs cognitive function [49] and has negative effects on cerebral neuroplasticity affecting dendritic arbor and synapses number in specific brain regions, including the hippocampus, amygdala and the prefrontal cortex. Chronic elevated levels of glucocorticoids may reduce memory processes (declarative memory) by affecting the normal hippocampal neuroplasticity and functionality [49] [50] [51]. Furthermore, stress-related events upon the prefrontal cortex may have deleterious actions in working memory (the short term memory that keep events in mind) which is also an executive function depending on frontal lobe normal functioning [52]. Not only chronic stress affects cognition, also anxiety by itself can modify executive functions. It has been proposed that anxiety as a personality trait reduces executive cognitive functions by impairing attention and task-switching capacity [53]. Gwada et al. recently found that low-anxious subjects showed an increased activation in the fronto-parietal networks, while highly anxious individuals showed a particular pattern of increased functioning of the cingulo-opercular and ventral attention favoring attention deficits [12]. In this study we did no found correlations between the severity of anxiety and verbal fluency but lower scores were found related to older age before treatment, in both semantic and phonemic verbal fluency. This finding suggests that anxiety may affect differently cognitive functions according age.

Limitations of this study must be mentioned: In this observational study we did not included a parallel control group, which is not allowed in a phase IV trial with highly symptomatic patients with inherent risks. Indeed, we could not compare the learning curve to determine the cognitive differences before and after treatment.

Cognitive tests were retested periodically during all the treatment period, principally to detect cognitive adverse events, nevertheless in this study we analyzed only at basal and at 12 weeks to determine the relationship within the clinical variables inside each period (basal: anxiety without treatment, and 12 weeks with alprazolam treatment).

\section{Conclusions}

In this study older age factor was associated with verbal fluency impairment in GAD patients.

Stratified treatments analyzing age and sex factors, including allostatic load measurements and cognitive assessments may be useful tools to determine the 
effectiveness and the safety of psychopharmacological treatments.

\section{Acknowledgements}

This study was funded with a partial grant from Gador SA, Buenos Aires and partial funds of the Henri Laborit Institute of Biosciences, Córdoba, Argentina. We want to thank Patricia Solís for her help in the study.

\section{Conflicts of Interest}

CAS and LD received a partial grant from Gador SA, Darwin 429, Buenos Aires City, Argentina. EJAR in an investigator employed by Gador SA. CR does not declare any conflict of interest.

\section{Patient Consent}

Obtained. All patients signed the informed consent for participating in this study.

\section{Ethics Approval}

An Independent Ethics Committee of FEFyM (Fundación de Estudios Farmacológicos y Medicamentos/Foundation for Pharmacological Studies and Drugs, Buenos Aires), and regulatory authorities of Argentina (ANMAT, Dossier \# 61409-8 of 20 April 2009), approved the protocol, following the law of Habeas Data and psychotherapeutic drug control.

\section{References}

[1] de Kloet, E.R., Joëls, M. and Holsboer, F. (2005) Stress and the Brain: From Adaptation to Disease. Nature Reviews Neuroscience, 6, 463-475. https://doi.org/10.1038/nrn1683

[2] de Kloet, E.R., Otte, C., Kumsta, R., Kok, L., Hillegers, M.H.J., Hasselmann, H., Kliegel, D. and Joëls, M. (2016) Stress and Depression: A Crucial Role of the Mineralocorticoid Receptor. Journal of Neuroendocrinology, 28.

https://doi.org/10.1111/jne.12379

[3] Mantella, R.C., Butters, M., Amico, J., Mazumdar, S., Rollman, B.L., Begley, A.E., Reynolds, C.F. and Lenze, E.J. (2008) Salivary Cortisol Is Associated with Diagnosis and Severity of Late-Life Generalized Anxiety Disorder. Psychoneuroendocrinology, 33, 773-781. https://doi.org/10.1016/j.psyneuen.2008.03.002

[4] Lahey, B.B. (2009) Public Health Significance of Neuroticism. American Psychologist, 4, 241-256. https://doi.org/10.1037/a0015309

[5] Plag, J., Gaudlitz, K., Schumacher, S., Dimeo, F., Bobbert, T., Kirschbaum, C. and Ströhle, A. (2014) Effect of Combined Cognitive-Behavioural Therapy and Endurance Training on Cortisol and Salivary Alpha-Amylase in Panic Disorder. Journal of Psychiatric Research, 58, 12-19. https://doi.org/10.1016/j.jpsychires.2014.07.008

[6] Garcia-Banda, G., Chellew, K., Fornes, J., Perez, G., Servera, M. and Evans, P. (2014) Neuroticism and Cortisol: Pinning down an Expected Effect. International Journal of Psychophysiology, 91, 132-138. https://doi.org/10.1016/j.ijpsycho.2013.12.005 
[7] McEwen, B.S. (2005) Stressed or Stressed out: What Is the Difference? Journal of Psychiatry \& Neuroscience, 30, 315-318.

[8] McEwen, B.S. and Gianaros, P.J. (2011) Stress- and Allostasis-Induced Brain Plasticity. Annual Review of Medicine, 62, 431-445.

https://doi.org/10.1146/annurev-med-052209-100430

[9] Tucha, O., Mecklinger, L., Laufkötter, R., Kaunzinger, I., Paul, G.M., Klein, H.E., and Lange, K.W. (2005) Clustering and Switching on Verbal and Figural Fluency Functions in Adults with Attention Deficit Hyperactivity Disorder. Cognitive Neuropsychiatry, 10, 231-248. https://doi.org/10.1080/13546800444000047

[10] Fenger, M.M., Gade, A., Adams, K.H., Hansen, E.S., Bolwig, T.G. and Knudsen, G.M. (2005) Cognitive Deficits in Obsessive-Compulsive Disorder on Tests of Frontal Lobe Functions. Nordic Journal of Psychiatry, 59, 39-44. https://doi.org/10.1080/08039480510018814

[11] Robinson, M.D. and Tamir, M. (2005) Neuroticism as Mental Noise: A Relation between Neuroticism and Reaction Time Standard Deviations. Journal of Personality and Social Psychology, 89, 107-114. https://doi.org/10.1037/0022-3514.89.1.107

[12] Gawda, B. and Szepietowska, E. (2016) Trait Anxiety Modulates Brain Activity during Performance of Verbal Fluency Tasks. Frontiers in Behavioral Neuroscience, 10, 1-15.

[13] Maubach, K. (2003) GABAA Receptor Subtype Selective Cognition Enhancers. Current Drug Targets-CNS \& Neurological Disorders, 2, 233-239.

[14] Wu, C.S., Wang, S.C. and Chang, I.S. (2009) The Association between Dementia and Long-Term Use of Benzodiazepine in the Elderly: Nested Case-Control Study Using Claims Data. The American Journal of Geriatric Psychiatry, 17, 614-620. https://doi.org/10.1097/JGP.0b013e3181a65210

[15] Tan, K.R. and Rudolph, U. (2011) Hooke Don Benzodiazepines: GABAA Receptor Subtypes and Addiction. Trends in Neurosciences, 34, 188-197. https://doi.org/10.1016/j.tins.2011.01.004

[16] Moylan, S., Staples, J., Ward, S.A., Rogerson, J., Stein, D.J. and Berk, M. (2011) The Efficacy and Safety of Alprazolam versus Other Benzodiazepines in the Treatment of Panic Disorder. Journal of Clinical Psychopharmacology, 31, 647-652. https://doi.org/10.1097/JCP.0b013e31822d0012

[17] Billioti, S., Gage, D., Bégaud, B. and Bazin, F. (2012) Benzodiazepine Use and Risk of Dementia: Prospective Population Based Study. BMJ, 345, e6231-e6231.

[18] Yaffe, K. and Boustani, M. (2014) Benzodiazepines and Risk of Alzheimer's Disease. BMJ, 349, 5312.

[19] Liu, D., Diorio, J., Tannenbaum, B., Caldji, C., Francis, D., Freedman, A., Sharma, S., Pearson, D., Plotsky, P.M. and Meaney, M.J. (1997) Maternal Care, Hippocampal Glucocorticoid Receptors, and Hypothalamic-Pituitary-Adrenal Responses to Stress. Science, 277, 1659-1662. https://doi.org/10.1126/science.277.5332.1659

[20] Agarwal, S.D. and Landon, B.E. (2019) Patterns in Outpatient Benzodiazepine Prescribing in the United States. JAMA Network Open, 2, e187399.

[21] Soria, C.A., Remedi, C., Núñez, D.A., D’Alessio, L. and Roldán, E.J.A. (2015) Impact of Alprazolam in Allostatic Load and Neurocognition of Patients with Anxiety Disorders and Chronic Stress (GEMA): Observational Study Protocol. BMJ Open, 5, e007231. https://doi.org/10.1136/bmjopen-2014-007231

[22] Crimmins, E.M., Johnston, M., Hayward, M. and Seeman, T. (2003) Age Differences in Allostatic Load: An Index of Physiological Dysregulation. Experimental Geron- 
tology, 38, 731-734. https://doi.org/10.1016/S0531-5565(03)00099-8

[23] Seeman, T., Epel, E., Gruenewald, T., Karlamangla, A. and McEwen, B.S. (2010) Socio-Economic Differentials in Peripheral Biology: Cumulative Allostatic Load. Annals of the New York Academy of Sciences, 1186, 223-239. https://doi.org/10.1111/j.1749-6632.2009.05341.x

[24] Curtis, G.C., Abelson, J.L. and Gold, P.W. (1997) Adrenocorticotropic Hormone and Cortisol Responses to Corticotropin-Releasing Hormone: Changes in Panic Disorder and Effects of Alprazolam Treatment. Biological Psychiatry, 41, 76-85. https://doi.org/10.1016/S0006-3223(95)00578-1

[25] Wedekind, D., Bandelow, B., Broocks, A. and Hajak, G. (2000) Salivary, Total Plasma and Plasma Free Cortisol in Panic Disorder. Journal of Neural Transmission, 107, 831-837. https://doi.org/10.1007/s007020070062

[26] Suls, J. and Martin, R. (2005) The Daily Life of the Garden-Variety Neurotic: Reactivity, Stressor Exposure, Mood Spillover, and Maladaptive Coping. Journal of Personality, 73, 1485-1509. https://doi.org/10.1111/j.1467-6494.2005.00356.x

[27] Chaudieu, I., Beluche, I., Norton, J., Boulenger, J.-P., Ritchie, K. and Ancelin, M.L. (2008) Abnormal Reactions to Environmental Stress in Elderly Persons with Anxiety Disorders: Evidence from a Population Study of Diurnal Cortisol Changes. Journal of Affective Disorders, 106, 307-313. https://doi.org/10.1016/j.jad.2007.07.025

[28] Soria, C.A., Remedi, C., D’Alessio, L. and Roldán, E.J.A. (2018) Sex and Age-Related Differences in Neuroticism and Allostatic Load Index in Urban Patients with General Anxiety Disorder Treated with Alprazolam. Open Journal of Psychiatry, 8, 212-232. https://doi.org/10.4236/ojpsych.2018.83019

[29] Hamilton, M. (1969) Diagnosis and Ratings of Anxiety. The British Journal of Psychiatry, 3, 76-79.

[30] Costa, R.R. and McCrae, P.T. (1999) Inventario de Personalidad NEO revisado (NEO PI-R) e Inventario NEO reducido de Cinco Factores (NEO-FFI).

[31] Folstein, M.F. (1975) "Mini-Mental State": A Practical Method for Grading the Mental State of Patients for the Clinician. Psychiatry Research, 12, 189-198. https://doi.org/10.1016/0022-3956(75)90026-6

[32] American Psychiatric Association (1994) Diagnostic and Statistical Manual of Mental Disorders. 4th Edition.

[33] Lezak, M. (1995) Neuropschychogical Assessment. 3rd Edition.

[34] Granato, D., de Araújo Calado, V.Ô.M. and Jarvis, B. (2014) Observations on the Use of Statistical Methods in Food Science and Technology. Food Research International, 55, 137-149. https://doi.org/10.1016/j.foodres.2013.10.024

[35] Woods, J.H. and Katz, J.L. (1992) Benzodiazepines: Use, Abuse, and Consequences. Pharmacological Reviews, 44, 151-347.

[36] Barker, M.J., Greenwood, K.M., Jackson, M. and Crowe, S.F. (2004) Persistence of Cognitive Effects after Withdrawal from Long-Term Benzodiazepine Use: A Meta-Analysis. Archives of Clinical Neuropsychology, 19, 437-454. https://doi.org/10.1016/S0887-6177(03)00096-9

[37] Ellinwood, E.H., Heatherly, D.G., Nikaido, A.M., Bjornsson, T.D. and Kilts, C. (1985) Psychopharmacology Comparative Pharmacokinetics and Pharmacodynamics of Lorazepam, Alprazolam and Diazepam. Intelligence, 392-399.

[38] Hek, K., Direk, N., Newson, R.S., Hofman, A., Hoogendijk, W.J.G., Mulder, C.L. and Tiemeier, H. (2013) Anxiety Disorders and Salivary Cortisol Levels in Older Adults: A Population-Based Study. Psychoneuroendocrinology, 38, 300-305. 
https://doi.org/10.1016/j.psyneuen.2012.06.006

[39] American Geriatrics Society, Beers Criteria Update Expert Panel (2012) American Geriatrics Society Updated Beers Criteria for Potentially Inappropriate Medication Use in Older Adults. Journal of the American Geriatrics Society, 60, 616-631. https://doi.org/10.1111/j.1532-5415.2012.03923.x

[40] Paterniti, S. and Dufouil, C. (2002) Long-Term Benzodiazepine Use and Cognitive Decline in the Elderly: The Epidemiology of Vascular Aging Study. Journal of Clinical Psychopharmacology, 22, 285-293. https://doi.org/10.1097/00004714-200206000-00009

[41] Boeuf-Cazou, O., Bongue, B., Ansiau, D., Marquié, J.-C. and Lapeyre-Mestre, M. (2011) Impact of Long-Term Benzodiazepine Use on Cognitive Functioning in Young Adults: The VISAT Cohort. European Journal of Clinical Pharmacology, 67, 1045-1052. https://doi.org/10.1007/s00228-011-1047-y

[42] Gallacher, J., Elwood, P., Pickering, J., Bayer, A. and Fish, M. (2012) Benzodiazepine Use and Risk of Dementia: Evidence from the Caerphilly Prospective Study (CaPS). Journal of Epidemiology and Community Health, 66, 869-873. https://doi.org/10.1136/jech-2011-200314

[43] Gray, S.L., Dublin, S., Yu, O., Walker, R., Anderson, M., Hubbard, R., Crane, P.K. and Larson, E.B. (2016) Benzodiazepine Use and Risk of Incident Dementia or Cognitive Decline: Prospective Population Based Study. BMJ, 352, i90. https://doi.org/10.1136/bmj.i90

[44] Yamada, S., Yamauchi, K., Yajima, J., Hisadomi, S., Maeda, H., Toyomasu, K. and Tanaka, M. (2000) Saliva Level of Free 3-Methoxy-4-Hydroxyphenylglycol (MHPG) as a Biological Index of Anxiety Disorders. Psychiatry Research, 93, 217-223. https://doi.org/10.1016/S0165-1781(00)00118-9

[45] Fries, E., Hellhammer, D.H. and Hellhammer, J. (2006) Attenuation of the Hypothalamic-Pituitary-Adrenal Axis Responsivity to the Trier Social Stress Test by the Benzodiazepine Alprazolam. Psychoneuroendocrinology, 31, 1278-1288. https://doi.org/10.1016/j.psyneuen.2006.09.009

[46] Zemishlany, D.M.Z., McQueeney, R. and Gabriel, S.M. (1990) Neuroendocrine and Monoaminergic Responses to Acute Administration of Alprazolam in Normal Subjects. Neuropsychobiology, 23, 124-128. https://doi.org/10.1159/000119437

[47] Coplan, J.D. (1997) Clinical Improvement with Fluoxetine Therapy and Noradrenergic Function in Patients with Panic Disorder. Archives of General Psychiatry, 54, 643. https://doi.org/10.1001/archpsyc.1997.01830190069007

[48] Yamamoto, K.I., Shinba, T. and Yoshii, M. (2014) Psychiatric Symptoms of Noradrenergic Dysfunction: A Pathophysiological View. Psychiatry and Clinical Neurosciences, 68, 1-20. https://doi.org/10.1111/pcn.12126

[49] Karatsoreos, I.N. and McEwen, B.S. (2013) Resilience and Vulnerability: A Neurobiological Perspective. F1000 Prime Reports, 5, 13.

[50] Sheline, Y.I., Wang, P.W., Gado, M.H., Csernansky, J.G. and Vannier, M.W. (1996) Hippocampal Atrophy in Recurrent Major Depression. Proceedings of the National Academy of Sciences, 93, 3908-3913. https://doi.org/10.1073/pnas.93.9.3908

[51] Sheline, Y.I., Sanghavi, M., Mintun, M. and Gado, M.H. (1999) Depression Duration But Not Age Predicts Hippocampal Volume Loss in Medically Healthy Women with Recurrent Major Depression. Journal of Neuroscience, 19, 5034-5043. https://doi.org/10.1523/JNEUROSCI.19-12-05034.1999

[52] Bergson, C. and Smiley, F. (1995) Regional, Cellular, and Subcellular Variations in the Distribution D, and D, Dopamine Receptors in Primate Brain. Journal of Neu- 
roscience, 15, 7821-7836. https://doi.org/10.1523/JNEUROSCI.15-12-07821.1995

[53] Eysenck, M.W., Derakshan, N., Santos, R. and Calvo, M.G. (2007) Anxiety and Cognitive Performance: Attentional Control Theory. Emotion, 7, 336-353.

https://doi.org/10.1037/1528-3542.7.2.336 